\title{
Correction to: Shadows Are Weaker
}

\section{Correction to:}

Chapter 4 in: J. Smith-Omomo, African Indigenous Financial Institutions, https://doi.org/10.1007/978-3-319-98011-9_4

Table 4.2 has been inadvertently published with a wrong format which is now updated in the proof as given below.

Table 4.2 Impactful institution types

\begin{tabular}{llll} 
& & Breadth & \\
\cline { 3 - 4 } & Low & High \\
\hline \multirow{2}{*}{ Depth } & High & $\begin{array}{l}\text { Commercial Institutions } \\
\text { Low }\end{array}$ & $\begin{array}{l}\text { High-Impact Institutions } \\
\text { Charitable Institutions }\end{array}$
\end{tabular}

The updated online version of this chapter can be found at https://doi.org/10.1007/978-3-319-98011-9_4 